Article

\title{
The Effects of the Downstream Contraction Ratio of Organ-Pipe Nozzle on the Pressure Oscillations of Self-Resonating Waterjets
}

\author{
Xiaoliang Wang ${ }^{1,3}$, Yong Kang ${ }^{1,3}$, Mengda Zhang ${ }^{1,3}$, Miao Yuan ${ }^{1,3}$ and Deng $\mathrm{Li}^{1,2,3, *(1)}$ \\ 1 Hubei Key Laboratory of Waterjet Theory and New Technology, Wuhan University, Wuhan 430072, China; \\ wx1773522415@126.com (X.W.); kangyong@whu.edu.cn (Y.K.); mengda93@whu.edu.cn (M.Z.); \\ yuanmiao125@live.com (M.Y.) \\ 2 School of Mechanical Science and Engineering, Huazhong University of Science and Technology, \\ Wuhan 430074, China \\ 3 School of Power and Mechanical Engineering, Wuhan University, Wuhan 430072, China \\ * Correspondence: 2008lee@whu.edu.cn; Tel.: +86-027-6877-4906
}

Received: 18 October 2018; Accepted: 8 November 2018; Published: 13 November 2018

\begin{abstract}
Self-resonating waterjets (SRWJs) are being widely used in the fields of energy exploitation, due to the significantly increased penetration rate of roller bits in deep-hole drilling. To further improve the impact and erosion abilities of SRWJs, the effects of the downstream contraction ratio of organ-pipe nozzle on the axial pressure oscillations were experimentally studied. The axial pressure oscillation peak and amplitude were used to evaluate the effects under two inlet pressures and various standoff distances. The results show that the downstream contraction ratio can affect the development trends of the pressure oscillations and determines the values of the peaks and amplitudes. Under the experimental conditions, 2.5 is the ratio that leads to the maximum peaks and amplitudes at almost all the testing standoff distances, while the ratio of 2 always results in the minimum ones. The development trend of the pressure oscillation peak for the ratio of 3.5 has a great change at an inlet pressure of $20 \mathrm{MPa}$. Generally, the relative pressure oscillations are more violent at an inlet pressure of $10 \mathrm{MPa}$, which is regardless of the contraction ratio. This study helps provide a guideline for determining the physical parameters required in the fabrication of organ-pipe nozzles used for deep-hole drilling.
\end{abstract}

Keywords: waterjet; self-resonance; contraction ratio; organ-pipe nozzle; pressure oscillation; deep-hole drilling

\section{Introduction}

Nowadays, with the rapid growth of the world population and the fast development of society and economy, energy consumption is dramatically increasing year by year [1-3]. The great demands for petroleum, coal, and natural gas are remarkably stimulating the development of efficient exploitation and deep-hole drilling for energy resources, as the shallow ones are being depleted gradually [4-7].

Aiming at improving the drilling efficiency, nozzles were used to increase the performance of roller bits since 1949 [8]. It is demonstrated that by using high-pressure fluid jets to assist the action of mechanical bits, the drilling rate can be two to three times faster than rates achieved by bits without nozzles installed [9]. From then on, the use of nozzles to produce fluid jets to augment the cutting action for maximizing the rate of penetration has been a standard feature in roller bit design. With the further development of hydro-energy resource exploration, it was found that cavitation, which easily occurs in high-speed flow, can greatly enhance the intensity of the drilling action [10]. Moreover, a feasibility study of cavitating nozzles with water as the working fluid has shown that the volume 
removal efficiency of drilling is much higher when compared with that of non-cavitating nozzles [11]. This is because the violent collapse of cavitation bubbles in the vicinity of solid boundaries is able to generate rather high-pressure pulses and high-speed micro-jets that can damage the materials being impacted [12]. Therefore, the employment of cavitating waterjets for improving the drilling speed has been a common action in the field of energy exploration.

However, in deep-hole drilling, the cavitation intensity is largely confined by the high ambient pressure, and the larger the drilling depth is, the stronger the confinement. This is due to the fact that the ambient pressure controls the cavitation number if the pressure drop across the nozzle has been determined, while the ambient pressure is in turn determined by the drilling depth. In order to solve this problem in deep-hole drilling, Conn and Radtke [13] proposed the concept of self-resonating waterjets (SRWJs), which combines the advantages of both a pulse jet and a cavitating jet. In their experiment, successful drilling tests were performed in a chamber which provided simulated wellbore pressures up to $21 \mathrm{MPa}$, and the results showed that organ-pipe nozzles produced more effective erosion action in comparison with conventional nozzles under the same operating conditions. Moreover, a comparison between organ-pipe nozzles and cylindrical center body nozzles by means of both laboratory tests and field trials showed that the former one provided greater volume removal and erosion rates in deep-hole drilling [14]. Subsequently, Johnson et al. [15] conducted a feasibility study on the erosion abilities of several nozzles that can generate SRWJs in deep-hole drilling, including the organ-pipe nozzle, "Pulser", "Pulser-Fed", and "Laid-back Pulser". They found that waterjets issued from "Pulser" were superior to those from organ-pipe nozzles with respect to the erosivity, but the big size made it impractical to be installed in the limited room available in the bits. Therefore, organ-pipe nozzles show the most promise of being adaptable to existing mechanical drill bits with only minor changes to the hydraulic passages in the bits [16]. Furthermore, Chahine et al. [17] extended the previous work by giving a comprehensive study on the self-resonant mechanisms of organ-pipe nozzles, and demonstrated that SRWJs are generated by taking full advantage of the natural tendency of an axisymmetric jet to organize into large structures, resulting in a large augmentation of the cutting action of mechanical deep-hole drilling bits.

Based on the self-resonant concept and the preliminary laboratory experiment results, Li et al. [18] conducted successful field trials in the petroleum engineering of China. They found that with the use of SRWJ, the rock erosion efficiency could be enhanced up to 2 times, and the average rates of penetration of tricone bits and bit footages could be increased by $31.2 \%$ and $29.1 \%$, respectively. Afterward, by using the optimized organ-pipe nozzles, they claimed that the average injection pressure of SRWJ could be reduced by $2.1 \mathrm{MPa}$ and the drilling rate in deep oil wells was considerably improved from $10.1 \%$ to $31.5 \%[19,20]$. Subsequently, SRWJs were employed in more than 40 oil wells and the results showed that this jet could afford an effective approach to improve the rate of penetration in deep and ultra-deep wells [21]. In recent years, SRWJs are still focused upon by a number of researchers. For example, Fang, et al. [22] numerically studied the characteristics of the flow field inside the organ-pipe nozzle in order to obtain the factors affecting the performance of SRWJ. Peng et al. [23] established a mathematic model to study the cavitation bubble size in the flow fields of SRWJs. Besides, Liu et al. [24] carried out an experiment to study the pressure characteristics of SRWJs with the use of Hilbert-Huang transform method. Ding et al. [25] took advantage of SRWJs to improve the mechanical properties of the aluminum alloy and claimed that the hardness and residual stress could be increased by $61.69 \%$ and $148 \%$, respectively. In addition, the authors have already conducted a series of experiments on SRWJs, such as the effects of the nozzle inner surface roughness, feeding pipe diameter, and the area discontinuity at the nozzle inlet on the characteristics of pressure oscillations and cavitation erosion of the jet [26-35]. 
Despite a great many investigations on SRWJ, it should be noticed that the optimal values of the downstream contraction ratio of organ-pipe nozzles are still unknown and need to be studied. So far, the organ-pipe nozzles used in the research are all manufactured using an equation that only gives the ratio of the chamber length to the exit diameter [13-22,25-32], and the detailed physical parameters required for fabricating an effective nozzle have not been reported.

This study is an attempt trying to understand the effects of the downstream contraction ratio of organ-pipe nozzles on the pressure oscillations of SRWJs through an experimental method. The pressure oscillation peak and amplitude of the jet were studied under four contraction ratio values and two inlet pressure values, and a non-dimensional analysis was also applied to better clarify the effects. The purpose of this study is to further improve the rate of penetration in deep-hole drilling for underground energy acquisition.

\section{SRWJ in Deep-Hole Drilling}

Due to the fact that organ-pipe nozzles offer the simplest system design among several kinds of self-resonating nozzles proposed [15,16], it has been widely used in the field of deep-hole drilling. So, this nozzle was used in this study, aiming at enhancing the rate of penetration of roller bits in deep-hole drilling. The working principles and geometry of organ-pipe nozzles are briefly shown below, and more detailed information can be found in the work done by Conn et al. [13-17].

As is illustrated in Figure 1, Organ-pipe nozzles producing SRWJs are embedded in the tricone drilling bit. During the working process of the bit, SRWJs issue from the nozzles and impinge on the solid surface. Then, the numerous cavitation bubbles formed in the jets collapse near or on the surface, generating high-speed micro jets and intense pressure waves that can greatly damage the target. On the other hand, the pressure pulsations also generate shock waves (regarded as the water hammer effect) that can damage both the surface and inner of the target [36]. As a result, the drilling efficiency is finally improved.

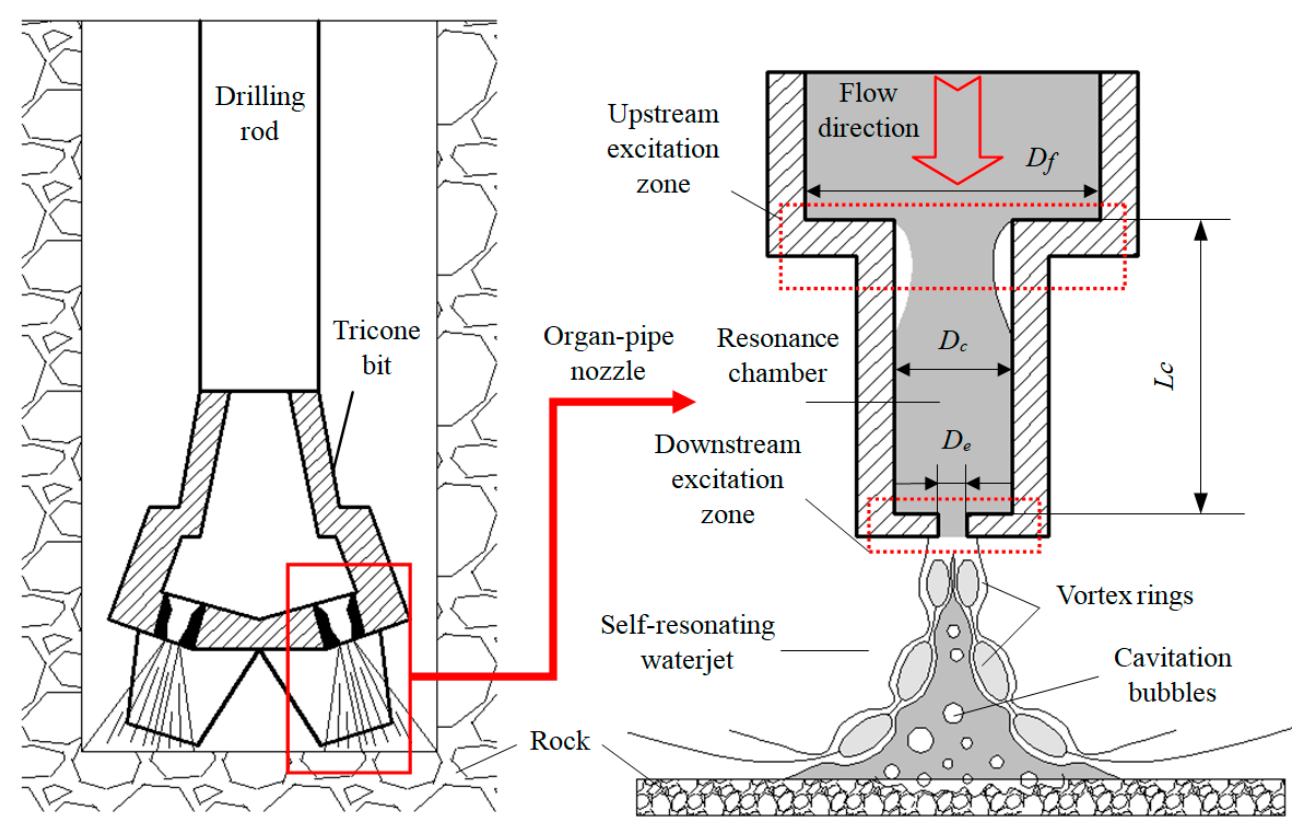

Figure 1. The schematic of the working principles and geometry of organ-pipe nozzles in deep-hole drilling. 
For the generation mechanism of SRWJs, it can be observed in Figure 1 that organ-pipe nozzles consist of an upstream area contraction of $\left(D_{f} / D_{c}\right)^{2}$, a downstream area contraction of $\left(D_{c} / D_{e}\right)^{2}$, and a resonance chamber with a length of $L_{c}$ and a diameter of $D_{c}$. Intense pressure waves are formed at the downstream contraction when high-speed fluid is passing through the nozzle, resulted in by the great and rapid changes of the flow velocity and pressure field. The pressure waves propagate upwards and reflected at the upstream area contraction because of the impedance change of the nozzle. Then, a standing wave will be formed in the chamber if $L_{c}$ meets the below equation [17,30]:

$$
L_{\mathrm{c}}=\left\{\begin{array}{l}
\frac{2 n-1}{4} \lambda \text { for }\left(\frac{D_{f}}{D_{c}}\right)^{2} \gg 1,\left(\frac{D_{f}}{D_{c}}\right)^{2} \gg 1 \\
\frac{n}{2} \lambda \quad \text { for }\left(\frac{D_{f}}{D_{\mathrm{e}}}\right)^{2} \gg 1,\left(\frac{D_{f}}{D_{c}}\right)^{2} \approx 1
\end{array} \quad(n=1,2,3 \cdots)\right.
$$

where $D_{f}$ is the inlet diameter, $\mathrm{m} ; D_{e}$ is the exit diameter, $\mathrm{m} ; n$ is a natural number, $\lambda$ is the length of the pressure wave, $\mathrm{m}$.

Finally, a peak resonance will occur in the chamber and an SRWJ is generated as long as the resonant frequency $\left(f_{0}\right)$ of the organ-pipe is near the critical jet structuring frequency $\left(f_{s}\right)$. The two frequencies are expressed as [15-17]

$$
\begin{gathered}
f_{0}=\frac{c}{\lambda} \\
f_{s}=\frac{S_{t} U_{e}}{D_{e}}
\end{gathered}
$$

where $S_{t}$ is the critical Strouhal number, with a general value of 0.3 used in SRWJ [13-17,35]; $U_{e}$ is the jet velocity, $\mathrm{m} / \mathrm{s}$; and $c$ is the local sound speed, $\mathrm{m} / \mathrm{s}$.

The peak resonance not only transfers the continuous jet into a pulsed one but also dramatically accelerates the cavitation in the flow by changing the jet structure into discrete ring vortex, which enables the jet to have a strong erosion ability. More specifically, the improved cavitation ability results from the increased number of bubbles that generated at the center of the vortex, and the passage of each ring vortex across the hole bottom generate substantial pressure fluctuations at the surface [16]. Besides, the pressure pulsations of the jet also transfer some energy to the cavitation [15]. More detailed descriptions of the generation of SRWJ can be found in [14-17].

Therefore, it should be obvious that the downstream area contraction contributes most to the generation of the pressure waves and the resonance because of the greater changes in the flow field. Therefore, this study focuses on the influence of the downstream area contraction on the characteristics of the axial pressure oscillation of SRWJ.

\section{Experimental Setup and Procedures}

In the present study, the axial pressure oscillation characteristics were used to evaluate the effects of the downstream contraction ratio. Thus, an experiment was designed to obtain the values of the pressure oscillation peak and amplitude. A schematic diagram of the experimental setup for measuring the axial pressures of SRWJs under different values of the downstream contraction ratio is shown in Figure 2. It should be noticed that the experimental method and the main equipment and facilities shown in the figure were all the same with those used in our previous investigations [25-32], except for the organ-pipe nozzles. Therefore, the schematic of the experimental set-up is the same as the previous ones [31,35]. 


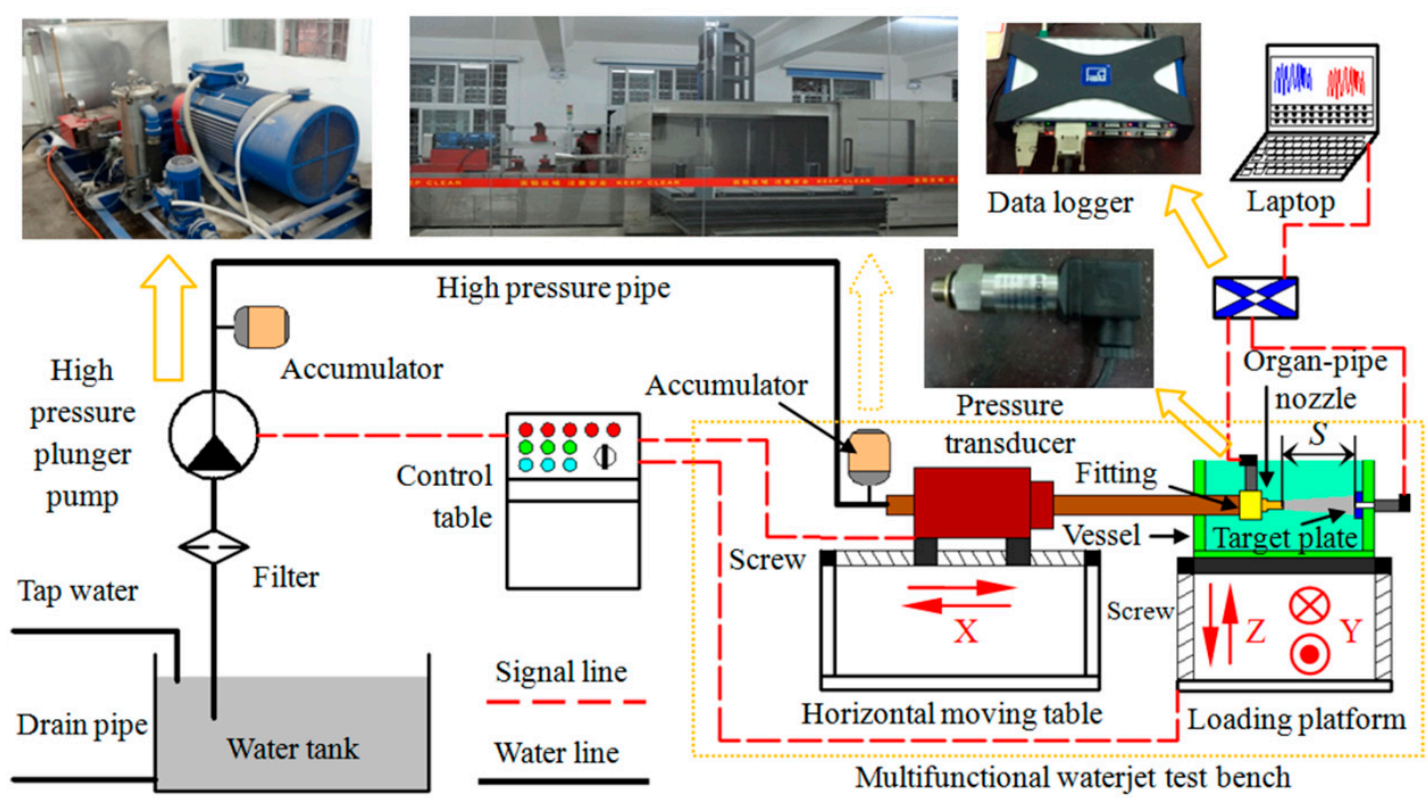

Figure 2. The schematic of the experimental setup for measuring the axial pressures [28,33-35].

During the testing process, tap water from the tank was pressurized by a high-pressure plunger pump and then reached the organ-pipe nozzle through high-pressure pipes. Then, the SRWJ issued from the nozzle and impinged on the surface of a target plate that had a pressure tap of $1 \mathrm{~mm}$ diameter at the center. The target plate was fixed on the wall of a vessel filled with water and the organ-pipe nozzle was mounted at the end of a hollow-rod settled on the horizontal moving table, as shown in Figure 2. The axis of the nozzle was made coaxial with that of the pressure tap by adjusting the positions of the vessel in the $Y$ and $Z$ directions. Finally, the axial pressure was obtained by a pressure transducer (Model: XPM 10) of a high frequency that communicated with the pressure tap. The pump had a maximum pressure of $60 \mathrm{MPa}$ and a maximum flow rate of $120 \mathrm{~L} / \mathrm{min}$. Moreover, two bladder accumulators were used to maximally attenuate the disturbances generated by the pump so as to avoid influences on the accuracy of the experimental results. To be more specific, one accumulator was located near the pump and the other one was placed close to the nozzle, shown in the figure. A static pressure transducer (Model: DMK 331P) was employed in the experiment, used to monitor the inlet pressure $\left(P_{i}\right)$ In addition, two inlet pressures of $10 \mathrm{MPa}$ and $20 \mathrm{MPa}$ were used in the experiment, which was determined by the pressure of the SRWJ used in practical applications of deep-hole drilling $[13,15]$. The main parameters of the transducers are shown in Tables 1 and 2, respectively, and FS means full scale.

Table 1. The main parameters of the pressure transducer of DMK 331P.

\begin{tabular}{ccc}
\hline Made & Parameter & Value \\
\hline & Nominal pressure $(\mathrm{MPa})$ & 40 \\
& Burst pressure $(\mathrm{MPa})$ & 100 \\
BD Sensors & Accuracy & $\leq \pm 0.5 \% \mathrm{FS}$ \\
& Influence effects of supply $(10 \mathrm{~V})$ & $0.05 \% \mathrm{FS}$ \\
& Influence effects of load $(\mathrm{k} \Omega)$ & $0.05 \%$ \\
& Thermal error $(10 \mathrm{~K})$ & $\pm 0.5 \% \mathrm{FS}$ \\
\hline
\end{tabular}


Table 2. The main parameters of pressure transducer of XPM 10.

\begin{tabular}{ccc}
\hline Made & Parameter & Value \\
\hline & Nominal pressure (MPa) & 35 \\
& Burst pressure (MPa) & 105 \\
Measurement $_{\text {SPECIALTIESTM }}$ & Frequency response (KHz) & 288 \\
& Accuracy & $\leq \pm 0.25 \% \mathrm{FS}$ \\
& Repeatability & $\pm 0.2 \%$ \\
& Nonlinearity & $\pm 0.25 \%$ \\
\hline
\end{tabular}

The pressure oscillation peak $\left(P_{\max }\right)$ and amplitude $\left(P_{a}\right)$ of SRWJs were used to evaluate the effects of the downstream contraction ratio. Furthermore, $P_{\max }$ and the minimum pressure $\left(P_{\min }\right)$ can be obtained from the laptop connected with the data logger, and $P_{a}$ was defined as the difference of $P_{\text {max }}$ and $P_{\text {min }}$, which is $P_{a}=P_{\text {max }}-P_{\text {min }}$. The standoff distance, $S$, which was defined as the distance from the nozzle exit to the surface of the target plate, varied from $10 \mathrm{~mm}$ to $100 \mathrm{~mm}$ during each test.

For the organ-pipe nozzles used in the experiment, four contraction ratio values were used, which were 2, 2.5, 3, and 3.5. All the nozzles had the same inlet and exit diameters of $13 \mathrm{~mm}$ and $2 \mathrm{~mm}$, respectively, determined from the previous study performed by Li et al. [18-21]. By making $f_{0}$ and $f_{\mathcal{S}}$ equal, the relation of $L_{c}$ and $D_{e}$ can be obtained based on Equations (1)-(3):

$$
f_{0}=f_{s} \Rightarrow \frac{L_{c}}{D_{e}}=\frac{K_{n} c}{U_{e} S_{t}}
$$

where $K_{n}$ is defined as the mode number and can be expressed as

$$
K_{n}=f u n c\left(n, \frac{D_{c}}{D_{e}}, M_{a}\right)= \begin{cases}\frac{2 n-1}{4} \lambda \text { for }\left(\frac{D_{f}}{D_{c}}\right)^{2} \gg 1,\left(\frac{D_{f}}{D_{c}}\right)^{2} \gg 1 \\ \frac{n}{2} \lambda \text { for }\left(\frac{D_{f}}{D_{\mathrm{e}}}\right)^{2} \gg 1,\left(\frac{D_{f}}{D_{c}}\right)^{2} \approx 1\end{cases}
$$

where Ma is the Mach number, defined as the ratio of the flow velocity to the local sound speed, $M a=U_{e} / c$.

Finally, by applying the Bernoulli equation [27] and Equation (4), the chamber lengths can be achieved, which were $21 \mathrm{~mm}$ and $15 \mathrm{~mm}$, corresponding to the two inlet pressures of $10 \mathrm{MPa}$ and $20 \mathrm{MPa}$. With respect to the pressure loss across the nozzle, more detailed information of the calculation process can be found in our previous research [27,35]. The picture of the nozzles is shown in Figure 3 and the parameters of the nozzles are summarized in Table 3.

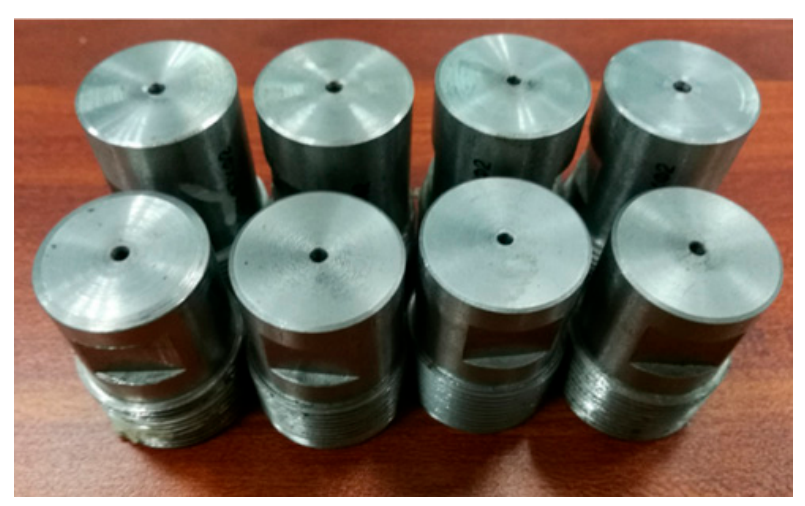

Figure 3. The picture of the organ-pipe nozzles. 
Table 3. The parameters of the organ-pipe nozzles used in the experiment.

\begin{tabular}{|c|c|c|c|c|c|c|c|}
\hline$P_{i}(\mathrm{MPa})$ & $D_{f}(\mathrm{~mm})$ & & $D_{c}$ & & & $D_{e}(\mathrm{~mm})$ & $L_{c}(\mathrm{~mm})$ \\
\hline 10 & \multirow{2}{*}{13} & \multirow{2}{*}{2} & \multirow{2}{*}{2.5} & \multirow{2}{*}{3} & \multirow{2}{*}{3.5} & \multirow{2}{*}{2} & 21 \\
\hline 20 & & & & & & & 15 \\
\hline
\end{tabular}

\section{Results and Discussion}

\subsection{Axial Pressure Oscillations at an Inlet Pressure of $10 \mathrm{MPa}$}

The axial pressure of SRWJs as a function of the standoff distance under the four different downstream contraction ratios and the inlet pressure of $10 \mathrm{MPa}$ was plotted, with the pressure oscillation peak and amplitude shown in Figure $4 \mathrm{a}, \mathrm{b}$, respectively. It is obvious that the downstream contraction ratio significantly affects the characteristics of the axial pressure oscillations. In more specific terms, the ratio of 2.5 always creates maximum pressure oscillation peaks and amplitudes at almost all the testing standoff distances, while the ratio of 2 always creates minimum ones. Only under the contraction ratio of 2.5 , do both the pressure oscillation peak and amplitude experience a slight increase and then an obvious decrease with the increase of the standoff distance, which is in good agreement with the experimental results obtained by Li et al. [18-21]. Moreover, it should be noticed that this development trend of the pressure oscillation peak and amplitude is a typical feature of SRWJs that had been demonstrated by Johnson et al. [15], Chahine et al. [17], and Li et al. [19]. In addition, the results of our previous research have also confirmed this typical feature of SRWJ [29-31,35]. So, that is to say, at an inlet pressure of $10 \mathrm{MPa}$, only organ-pipe nozzles with a downstream contraction ratio of 2.5 can generate effective SRWJ that has large pressure oscillations. According to the generation mechanism of SRWJ [17], it can be claimed that the downstream contraction ratio determines the intensity of self-resonance in the chamber, as well as the effectiveness of the SRWJ. In other words, the downstream contraction ratio of 2.5 triggers the strongest self-resonance that results in the largest pressure oscillation peaks and amplitudes. It can be claimed that 2.5 is the preferred downstream contraction ratio under the inlet pressure of $10 \mathrm{MPa}$ in the fabrication of organ-pipe nozzles, while the ratio of 2 should be avoided.

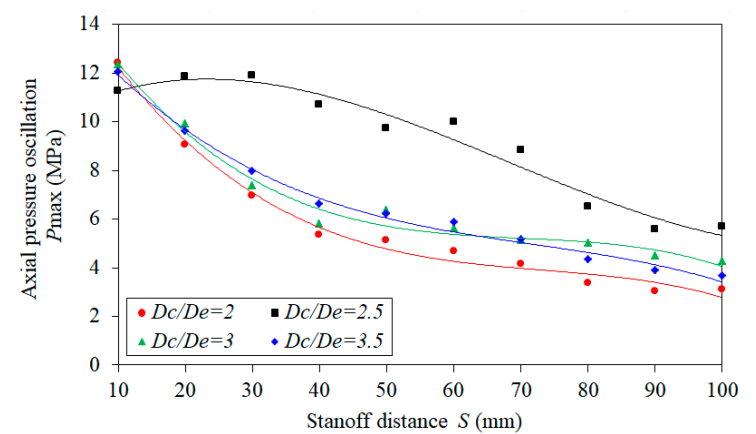

(a)

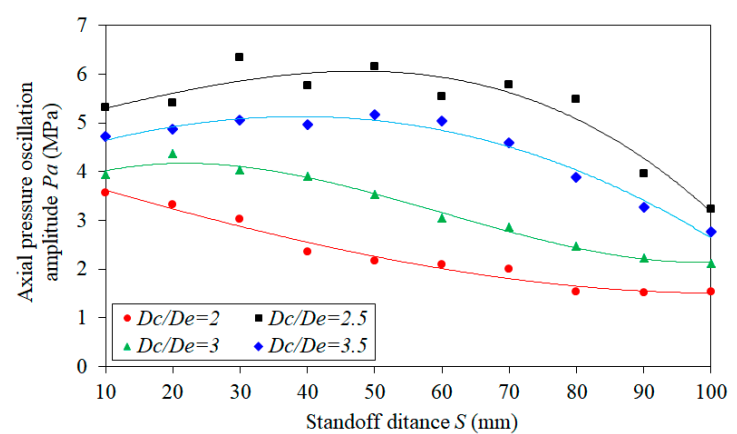

(b)

Figure 4. The axial pressure oscillation (a) peak and (b) amplitude against the standoff at an inlet pressure of $10 \mathrm{MPa}$.

For the pressure oscillation peak shown in Figure 4a, the development trend against the standoff distance under the contraction ratio of 2 is obviously different from that under the other ratios. Besides, it is of great interest to observe that the development trends under the contraction ratios of 2, 3, and 3.5 are nearly the same, with the peak dropping with increasing standoff distance all the time. Moreover, the peaks under these three contraction ratios at each standoff distance are very close and have large differences when compared with those values under the ratio of 2 . These phenomena indicate that the 
value of the downstream contraction ratio is significantly important for the generation of relatively large pressure oscillation peaks.

With respect to the pressure oscillation amplitude shown in Figure $4 \mathrm{~b}$, it is observed that the values of the amplitude under the four contraction ratios at each standoff distance are obviously different. However, the development trends are very similar, except for the case of the ratio of 2, which slightly drops with the increasing standoff distance. When compared with the pressure oscillation peak in Figure 4a, it was found that the pressure oscillation amplitude is more sensitive to the variations of the downstream contraction ratio, especially for the cases of ratios of 2,3, and 3.5. To be more specific, the contraction ratio of 3.5 is superior to the ratio of 3 for getting larger amplitudes under an inlet pressure of $10 \mathrm{MPa}$.

However, it should be pointed out that these analyses are preliminary and qualitative to some degree due to the complexity of the SRWJ and the very limited literature in this field.

\subsection{Axial Pressure Oscillations at an Inlet Pressure of $20 \mathrm{MPa}$}

Under $n$ inlet pressure of $20 \mathrm{MPa}$, the axial pressure oscillation peak and amplitude against the standoff distance were also plotted, shown in Figure 5a,b, respectively. The contraction ratio of 2.5 still results in both the maximum peaks and amplitudes, which is the same with that under the inlet pressure of $10 \mathrm{MPa}$ shown in Figure 4. Besides, the typical trends of SRWJs for this contraction ratio is more obvious under the increased inlet pressure, which is in consist with the previous experimental results [18-21]. Furthermore, another interesting phenomenon observed is that the contraction ratio of 2 still leads to minimum peaks and amplitudes at almost all the standoff distances. So, 2.5 is still the optimal value of the downstream contraction ratio, while 2 should also be avoided. Moreover, except for the case of 3.5, the development trends of the pressure oscillation peak and amplitude for all the other ratios remain the same under the two inlet pressures, indicating that the inlet pressure can hardly change this feature. However, it should be pointed out that the development trend of the pressure oscillation peak for the contraction ratio of 3.5 has a dramatic change with the increased inlet pressure. In addition, it can be observed that the development trends of the pressure oscillation peak and amplitude for this case also have the mentioned typical feature of SRWJs. That is to say, both the downstream contraction ratio of 2.5 and 3.5 make effective and obvious SRWJs under an inlet pressure of $20 \mathrm{MPa}$.

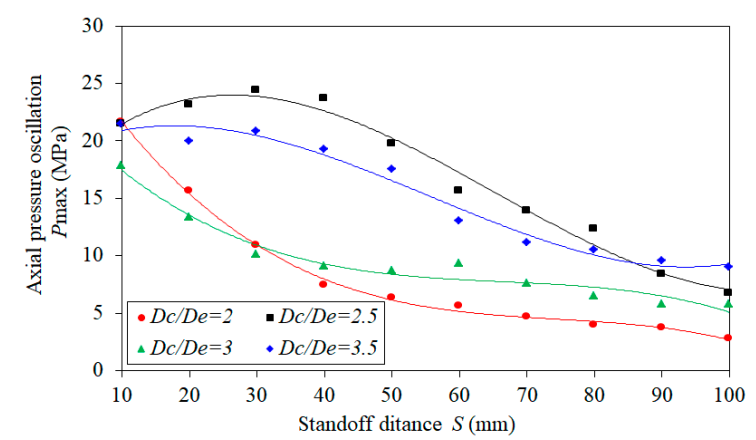

(a)

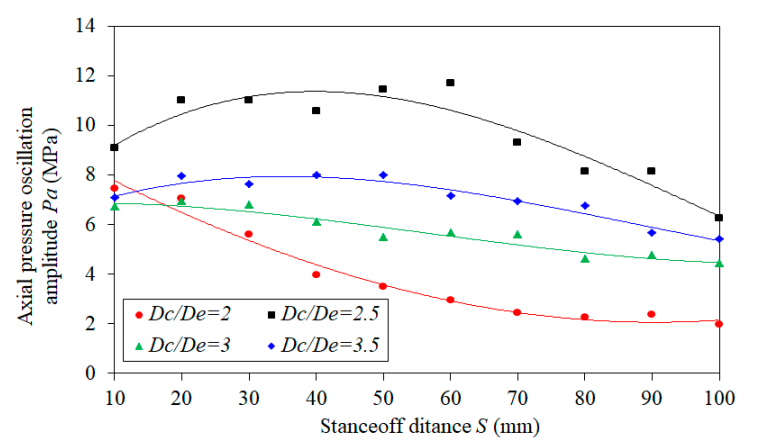

(b)

Figure 5. The axial pressure oscillation (a) peak and (b) amplitude against the standoff at an inlet pressure of $20 \mathrm{MPa}$.

To be more specific, the pressure oscillation peaks for the contraction ratios of 2.5 and 3.5 are obviously greater than those for the ratios of 2 and 3, especially at standoff distances between $20 \mathrm{~mm}$ and $70 \mathrm{~mm}$. Since this range of standoff distance is where the cavitation bubbles and large ring vortex are formed and take effect [32], it again indicates that the contraction ratio has affected the self-resonance in the chamber. More specifically, even the pressure oscillation peak for the contraction ratio of 2 is larger than that for the ratio of 3 at standoff distances below $30 \mathrm{~mm}$ and it rapidly drops 
to the minimum with further increasing standoff distance. With respect to the pressure oscillation amplitude shown in Figure 5b, it can be observed that the inlet pressure has very little ability to change the developing trends, nor the order of ratios for yielding larger pressure oscillation amplitudes.

\subsection{Non-Dimensional Analysis of the Pressure Oscillations}

Non-dimensional analysis is known as a dramatically important method used to extract the dimensionless groups that affect the solution of a number of complex problems [37]. In order to further clarify the characteristics of the pressure oscillations, a preliminary non-dimensional analysis was performed. According to the previous research [17], the axial pressure oscillation peak and amplitude were nondimensionalized by the inlet pressure and the standoff distance was nondimensionalized by the exit diameter of the nozzle. The averaged peak and amplitude at each standoff distance were calculated and displayed, and the trendlines including the correlation coefficients are also provided in the figures. The dimensionless pressure oscillation peak and amplitude against the dimensionless standoff distance are shown in Figures 6 and 7, respectively.

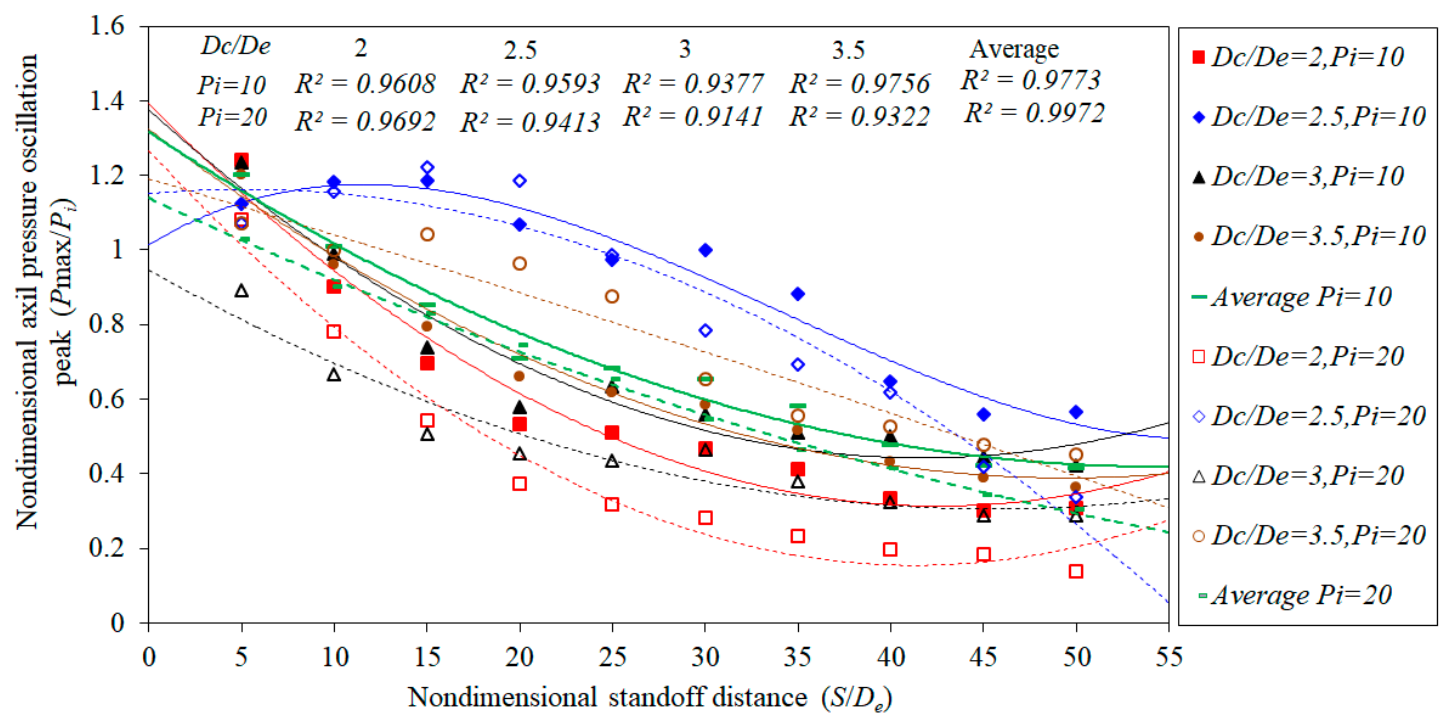

Figure 6. The dimensionless pressure oscillation peak against the dimensionless standoff distance.

As is illustrated in Figure 6, the dimensionless pressure oscillation peaks under the two inlet pressures are very close to each other at each standoff distance for the contraction ratio of 2.5. It is also found that the dimensionless peak only has a slight increase in this contraction ratio. For all the other cases, the dimensionless peak always decreases with the dimensionless standoff distance. For the curves of the same color, all the solid ones are above the corresponding dash ones, except for the brown ones. That is to say the dimensionless pressure oscillation peak at an inlet pressure of $10 \mathrm{MPa}$ is greater than that at an inlet pressure of $20 \mathrm{MPa}$ for the contraction ratio of 2, 2.5, and 3 . Moreover, it is found that the trendlines of the dimensionless peak for the same contraction ratio are more likely to be parallel at a dimensionless standoff distance between 15 and 40 , as well as the average ones. It is also evidence that inlet pressure is hard to change the developing trends of the pressure oscillation peak under different downstream contraction ratios. Besides, the difference between the trendlines of the averaged dimensionless peak is rather small.

As is shown in Figure 7, the curves are generally concentrated at both ends of the horizontal axis, while in the middle section they are kind of dispersive, indicating that the effects of the downstream contraction ratio on the pressure oscillation amplitude are more obvious during a certain range of standoff distance values. It is also observed that the solid curves are above the dashed curves of the same color nearly all the time, meaning that the relative pressure oscillation amplitude is greater at an inlet pressure of $10 \mathrm{MPa}$. Furthermore, the largest difference between the curves of the same color 
appears between the brown ones, indicating that the relative pressure oscillation amplitude at an inlet pressure of $10 \mathrm{MPa}$ is much greater than that at an inlet pressure of $20 \mathrm{MPa}$ for the contraction ratio of 3.5. When taking the dimensionless pressure oscillation peak into consideration, it can be claimed that the pressure oscillation of SRWJs is generally more violent at an inlet pressure of $10 \mathrm{MPa}$, which means the relative intensity of self-resonance and performance of SRWJ are greater. This is mainly because the energy loss is higher, caused by the increased flow velocity at greater inlet pressures [32].

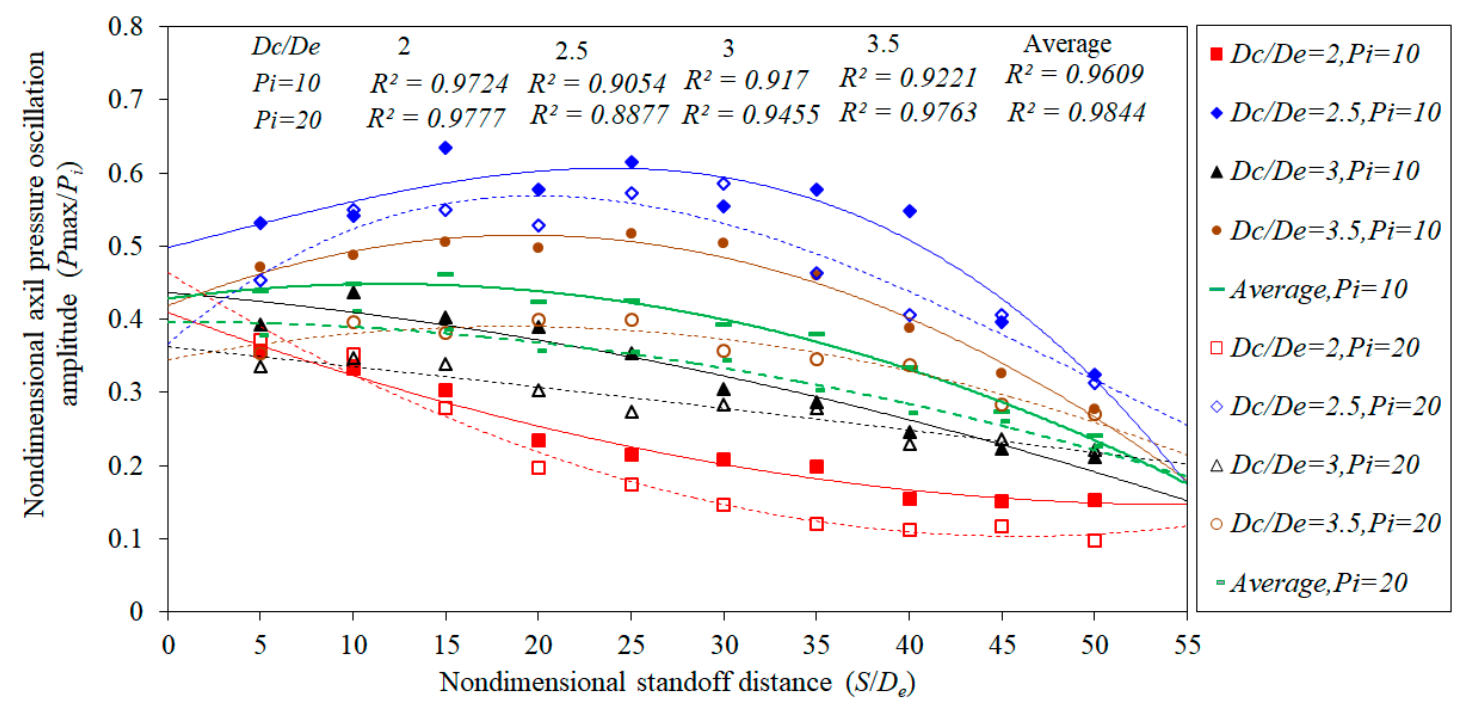

Figure 7. The dimensionless pressure oscillation amplitude against dimensionless standoff distance.

Still, it should be noticed that the current lack of related theoretical and empirical research in the literature makes it rather hard to give a detail illustration of the reasons behind the foregoing phenomena.

\section{Conclusions}

For the purpose of enhancing the rate of penetration of deep-hole drilling for underground energy acquisition, the performances of organ-pipe nozzles with different downstream contraction ratios were studied by evaluating the axial pressure oscillations. Even though this study is preliminary, it still provides important information for improving the erosion and impact effects of SRWJs, as well as the drilling efficiency. The main conclusions are summarized as follows:

(1) Under the experimental conditions, a downstream contraction ratio of 2.5 leads to both maximum pressure oscillation peaks and amplitudes at all the testing standoff distances, while a ratio of 2 always results in the minimum ones.

(2) An organ-pipe nozzle with a contraction ratio of 2.5 generates effective SRWJ at both inlet pressures, while a nozzle with the ratio of 3.5 also creates a waterjet possessing the typical feature of SRWJ when inlet pressure increased to $20 \mathrm{MPa}$.

(3) The inlet pressure can hardly affect the development trends of the pressure oscillation peak and amplitude against the standoff distance. Except for the case of 3.5, the development trends of the pressure oscillation peak and amplitude for all the other ratios remain the same under the two inlet pressures.

(4) The dimensionless pressure oscillation peak only has a slight increase in the contraction ratio of 2, and the pressure oscillation of SRWJs is generally more violent at an inlet pressure of $10 \mathrm{MPa}$.

(5) Further studies related to the resonating frequency and the exact characteristics of the pressure waves should be conducted in order to theoretically and mathematically clarify the mechanism of the influence of the downstream contraction ratio. 
Author Contributions: For research articles with several authors, a short paragraph specifying their individual contributions must be provided. The following statements should be used "Conceptualization, D.L.; Methodology, D.L. and X.W.; Writing-Original Draft Preparation, X.W. and M.Y.; Writing-Review \& Editing, D.L. and M.Z.; Supervision, Y.K.; Project Administration, Y.K.; Funding Acquisition, D.L.", please turn to the CRediT taxonomy for the term explanation. Authorship must be limited to those who have contributed substantially to the work reported.

Funding: This research is financially supported by the National Natural Science Foundation of China (No.51805188) and the China Postdoctoral Science Foundation Founded Project (No.2017M620313).

Acknowledgments: In this section you can acknowledge any support given which is not covered by the author contribution or funding sections. This may include administrative and technical support, or donations in kind (e.g., materials used for experiments).

Conflicts of Interest: The authors declare no conflict of interest.

\section{References}

1. Li, P.; Zhang, J.S. A New Hybrid Method for China's Energy Supply Security Forecasting Based on ARIMA and XGBoost. Energies 2018, 11, 29. [CrossRef]

2. Beraldi, P.; Violi, A.; Bruni, M.E.; Carrozzino, G. A Probabilistically Constrained Approach for the Energy Procurement Problem. Energies 2017, 10, 2179. [CrossRef]

3. Otsuka, A. Regional Determinants of Energy Efficiency: Residential Energy Demand in Japan. Energies 2018, 11, 14. [CrossRef]

4. Ranjith, P.; Zhao, J.; Ju, M.; Silva, R.; Rathnaweera, T.; Bandara, A. Opportunities and challenges in deep mining: A brief review. Engineering 2017, 3, 546-551. [CrossRef]

5. Thomas, C. Stopping Climate Change: The Case for Hydrogen and Coal; Springer: Cham, Switzerland, 2017; pp. 35-40, ISBN 978-3-319-31654-3.

6. Taherdangkoo, R.; Taherdangkoo, M. Modified stem cells algorithm-based neural network applied to bottom hole circulating pressure in underbalanced drilling. Int. J. Pet. Eng. 2015, 1, 178-188. [CrossRef]

7. Tatomir, A.; McDermott, C.; Bensabat, J.; Class, H.; Edlmann, K.; Taherdangkoo, R.; Sauter, M. Conceptual model development using a generic Features, Events, and Processes (FEP) database for assessing the potential impact of hydraulic fracturing on groundwater aquifers. Adv. Geosci. 2018, 45, 185-192. [CrossRef]

8. Maurer, W.; Heilhecker, J.; Love, W. High pressure drilling. J. Pet. Technol. 1973, 255, 851-859. [CrossRef]

9. Maurer, W. The perfect-cleaning theory of rotary drilling. J. Pet. Technol. 1962, 14, 1270. [CrossRef]

10. Li, Z. Criteria for jet cavitation and cavitation jet drilling. Int. J. Rock Mech. Min. Sci. 2014, 71, $204-207$. [CrossRef]

11. Conn, A.; Radtke, R. Cavitating bit jets promise faster drilling for deep-hole operations. Oil Gas J. 1977, 75, 129-146. [CrossRef]

12. Peng, K.; Tian, S.; Li, G.; Alehossein, H. Mapping cavitation impact field in a submerged cavitating jet. Wear 2018, 396, 22-33. [CrossRef]

13. Conn, A.; Radtke, R. CAVIJET ${ }^{\mathrm{TM}}$ augmented deep-hole drilling bits. J. Press. Vessel Technol. 1978, 100, 52-59. [CrossRef]

14. Conn, A.; Johnson, V.; Liu, H.; Frederick, G. Evaluation of CAVIJET Cavitating Jets for Deep-Hole Rock Cutting; SAND-81-7067, Technical Report; U.S. Department of Energy Office of Scientific and Technical Information: Oak Ridge, TN, USA, 1981. Available online: https://www.osti.gov/biblio/6515979 (accessed on 24 April 2017).

15. Johnson, V.; Lindenmuth, W.; Conn, A.; Frederick, G. Feasibility Study of Tuned-Resonator, Pulsating Cavitating Water Jet for Deep-Hole Drilling; SAND-81-7126, Technical Report; Department of Energy Office of Scientific and Technical Information: Oak Ridge, TN, USA, 1981. Available online: https://www.osti.gov/biblio/ 6266875 (accessed on 24 April 2017).

16. Johnson, V.; Chahine, G.; Lindenmuth, W.; Conn, A.; Frederick, G.; Giacchino, G. Cavitating and structured jets for mechanical bits to increase drilling rate-Part I: Theory and concepts. J. Energy Resour. Technol. 1984, 106, 282-288. [CrossRef]

17. Chahine, G.; Johnson, V. Mechanics and applications of self-resonating cavitating jets. Proc. Int. Symp. Jets Cav. ASME 1985, 15, 21-33. 
18. Li, G.; Zhang, D.; Shen, Z. An experimental study on pressure attenuation of self-resonating cavitation jet under ambient pressure. In Proceedings of the International Symposium on New Applications of Water Jet Technology, Isinomaki, Japan, August 1999.

19. Li, G.; Shen, Z.; Zhou, C.; Zhang, D.; Chen, H. Investigation and application of self-resonating cavitating water jet in petroleum engineering. Pet. Sci. Technol. 2005, 1, 1-15.

20. Li, G.; Shi, H.; Liao, H.; Shen, Z.; Niu, J.; Huang, Z.; Luo, H. Hydraulic pulsed cavitating jet-assisted drilling. Pet. Sci. Technol. 2009, 27, 197-207. [CrossRef]

21. Li, G.; Shi, H.; Niu, J.; Huang, Z.; Tian, S.; Song, X. Hydraulic pulsed cavitating jet assisted deep drilling: An approach to improve rate of penetration. In Proceedings of the International Oil and Gas Conference and Exhibition in China, Beijing, China, 8-10 June 2010.

22. Fang, Z.; Kang, Y.; Wang, X.; Li, D.; Hu, Y.; Huang, M.; Wang, X. Numerical and experimental investigation on flow field characteristics of organ pipe nozzle. In Proceedings of the IOP Conference Series: Earth and Environmental Science, Montreal, QC, Canada, 22-26 September 2014.

23. Peng, K.; Tian, S.; Li, G.; Huang, Z.; Yang, R.; Guo, Z. Bubble dynamics characteristics and influencing factors on the cavitation collapse intensity for self-resonating cavitating jets. Pet. Explor. Dev. 2018, 45, 343-350. [CrossRef]

24. Liu, W.; Kang, Y.; Zhang, M.; Wang, X.; Li, D.; Xie, L. Experimental and theoretical analysis on chamber pressure of a self-resonating cavitation waterjet. Ocean Eng. 2018, 151, 33-45. [CrossRef]

25. Ding, X.; Kang, Y.; Li, D.; Wang, X.; Zeng, D. Experimental investigation on surface quality processed by self-Excited oscillation pulsed waterjet peening. Materials 2017, 10, 989. [CrossRef] [PubMed]

26. Li, D.; Li, X.; Kang, Y.; Wang, X.; Long, X.; Wu, S. Experimental investigation on the influence of internal surface roughness of organ pipe nozzle on the characteristics of high pressure jet. J. Mech. Eng. 2015, 51, 169-176. (In Chinese) [CrossRef]

27. Li, D.; Kang, Y.; Ding, X.; Wang, X.; Fang, Z. Effects of Nozzle Inner Surface Roughness on the Performance of Self-Resonating Cavitating Waterjets under Different Ambient Pressures. Stroj. Vestn. J. Mech. Eng. 2017, 63, 92-102. [CrossRef]

28. Li, D.; Kang, Y.; Ding, X.; Liu, W. Experimental study on the effects of feeding pipe diameter on the cavitation erosion performance of self-resonating cavitating waterjet. Exp. Therm. Fluid Sci. 2017, 82, 314-325. [CrossRef]

29. Li, D.; Kang, Y.; Ding, X.; Wang, X.; Fang, Z. An experimental investigation on the pressure characteristics of high speed self-resonating pulsed waterjets influenced by feeding pipe diameter. J. Mech. Sci. Technol. 2016, 30, 4997-5007. [CrossRef]

30. Li, D.; Kang, Y.; Ding, X.; Wang, X.; Fang, Z. Effects of area discontinuity at nozzle inlet on the characteristics of self-resonating cavitating waterjet. Chin. J. Mech. Eng. 2016, 29, 813-824. [CrossRef]

31. Li, D.; Kang, Y.; Ding, X.; Liu, W. Effects of the geometry of impinging surface on the pressure oscillations of self-resonating pulsed waterjet. Adv. Mech. Eng. 2017, 9. [CrossRef]

32. Li, D.; Kang, Y.; Wang, X.; Ding, X.; Fang, Z. Effects of nozzle inner surface roughness on the cavitation erosion characteristics of high speed submerged jets. Exp. Therm. Fluid Sci. 2016, 74, 444-452. [CrossRef]

33. Li, D.; Kang, Y.; Ding, X.; Wang, X.; Fang, Z. Effects of area discontinuity at nozzle inlet on the characteristics of high speed self-excited oscillation pulsed waterjets. Exp. Therm. Fluid Sci. 2016, 79, 254-265. [CrossRef]

34. Li, D.; Kang, Y.; Ding, X.; Wang, X.; Liu, W. Effects of feeding pipe diameter on the performance of a jet-driven Helmholtz oscillator generating pulsed waterjets. J. Mech. Sci. Technol. 2017, 31, 1203-1212. [CrossRef]

35. Li, D.; Chen, Y.; Kang, Y.; Wang, Z.; Wang, X.; Fan, Q.; Yuan, M. Experimental investigation of the preferred Strouhal number used in self-resonating pulsed waterjet. J. Mech. Sci. Technol. 2018, 32, 4223-4229. [CrossRef]

36. Dehkhoda, S.; Hood, M. An experimental study of surface and sub-surface damage in pulsed water-jet breakage of rocks. Int. J. Rock Mech. Min. Sci. 2013, 63, 138-147. [CrossRef]

37. Conesa, M.; Pérez, J.S.; Alhama, I.; Alhama, F. On the nondimensionalization of coupled, nonlinear ordinary differential equations. Nonlinear Dynam. 2016, 84, 91-105. [CrossRef]

(C) 2018 by the authors. Licensee MDPI, Basel, Switzerland. This article is an open access article distributed under the terms and conditions of the Creative Commons Attribution (CC BY) license (http:// creativecommons.org/licenses/by/4.0/). 